\title{
Thermal Behavior Evaluation of Ventilated Roof under Variable Solar Radiation
}

\author{
Vincenzo Bianco ${ }^{1}$, Alessandra Diana ${ }^{1 *}$, Oronzio Manca ${ }^{2}$ and Sergio Nardini ${ }^{2}$ \\ ${ }^{1}$ Dipartimento di Ingegneria Meccanica, Energetica, Gestionale e dei trasporti, Università degli \\ Studi di Genova, Genova (GE), Italy \\ 2 Dipartimento di Ingegneria Industriale e dell'Informazione, Seconda Università degli Studi di \\ Napoli, Aversa (CE), Italy
}

Email: dialex.ad@gmail.com

\begin{abstract}
A ventilated roof has a good configuration for energy purposes, in order to respect the European Directive priority for building performance requirement to reduce energy consumption. In Mediterranean regions, with high level of solar radiation, the roof design should respect comfort and energy saving, considering that climatic conditions change depending on seasons and territories.

This paper illustrates a numerical investigation on a prototypal ventilated roof for residential use, in order to evaluate its thermofluidodynamic behaviors as a function of the solar radiation applied on the top wall of the roof simulating summer and winter conditions. The roof is modeled as a single side and it is analyzed as twodimensional, in air flow, thanks to the commercial code Ansys-Fluent. Results are given in terms of temperature and pressure distributions, air velocity and temperature profiles along longitudinal and cross sections of the ventilated layer, in order to estimate the differences between the various conditions. Ventilated roof configuration results significant to reach optimal thermal and hygrometric conditions in summer and winter conditions.
\end{abstract}

Keywords: Ventilated roof, Numerical investigation, Summer, Winter conditions, Energy saving, Heat flux, Heat transfer model, Fluent.

\section{INTRODUCTION}

One of the European Directive priorities is represented by the improvement of "building performance requirements" and the development of new strategies for "very low energy buildings". The goal, in particular, is the reduction of the energy consumptions due to the heat flux transmitted through the envelope of residential and commercial buildings. In regions, like Mediterranean region object of this study, with high level of solar radiation, the analysis of residential consumption shows that energy demand is mainly ascribable to environmental conditioning. Building surfaces are affected by local climate depending on orientation and inclination and, in particular, the top cover insulation is very important to reduce energy use. The roof design should respect comfort and energy saving, considering that climatic condition change depending on seasons and territories. In the winter period, the top cover should contain heat losses. In the summer period, the top cover should reduce the heat gain from the ambient to limit the consumption of the energy essential to the air conditioning system. A ventilated roof has a good configuration for energy purposes [1]. It is composed by a series of layers: the outermost layer is the roof cover: it protects the structure against chemical, physical and mechanical stresses of the external ambient. Immediately under the mantle, there is the ventilation layer: a cavity which goes from the eaves to the ridge, so the air can flow along the channel for the entire length of the roof. Thermal insulation of the roof is obtained thanks to one o more panels of insulating material. Rainwater infiltration and condensation percolation are prevented thanks to waterproof panels. Lastly, the structure is the element that holds permanent loads (the weight of the structure) and accidental overloads (weather elements) and resists to exceptional events (storms and earthquakes). The cooling effect of ventilation in the roof cavity is proved under real climatic condition and it is numerically verified testing geometrical parameters (air gap height, effect of the ridge, inclination of the slab) and thermal conditions [2-4]. Passive methods, like special roof systems in naturally ventilated residential buildings, are used to reduce the room cooling load in hot and humid climate $[5,6]$. In [7], 14 different roof constructions under continuously airconditioned and non-acclimatized regimes are studied to find the suitable roof configuration for warm climates in terms of thermal comfort of the users. In [8], double-skin roofs are numerically investigated and they are described as an emerging solution for passive cooling of buildings in tropical climate. Double-skin roofs are studied in [9]: they are composed by adding a metallic screen on an existing sheet metal roof. The system increases passive cooling of dwellings 
and decreases power costs for air conditioning in summer period or in tropical and arid countries. In [10] a full scale ventilated roof component is tested under real climatic condition: its improved performance is particularly significant in summer period. In fact, ventilation reduces the cooling load and the building energy demand [11] in summer, due to the surface shading and the heat removed by the air flow within the ventilation cavity. The effects of construction parameters are analyzed in summer and winter conditions and ventilated roof performances are more remarkable than a conventional roof $[12,13]$. Ventilated roof performances can be improved thanks to upgrading systems considering the different effects of summer and winter regimes [14-16]. Solar technologies [17, 18] improve the energy efficiency of several systems and climate changes promotes ventilated roofs due to there are more adaptable, even in problematic scenarios.

This paper illustrates a numerical investigation on a prototypal ventilated roof for residential use. The system has been studied considering a single side of the roof and the analysis is carried out on a two-dimensional model in air flow. The investigation is performed in order to evaluate thermofluidodynamic behaviors of the ventilated roof as a function of the solar radiation applied on the top wall of the roof to simulate summer and winter regimes. Results are given in terms of temperature and pressure distributions, air velocity and temperature profiles along different longitudinal and cross sections of the ventilated layer in order to estimate the differences between the various conditions.

\section{MATHEMATICAL MODEL AND NUMERICAL SOLUTION}

The physical domain under investigation is twodimensional and its configuration is geometrically and thermally symmetry, so a single side of the roof is considered, as shown in Figure 1. The optimal configuration for building insulation considers a ventilated roof composed by layers of several materials combined conveniently. The numerical model used in simulations is an inclined canne, with the upper line and the bottom line simulating respectively the properties of all layers above and under the ventilated channel. The channel has a length, $\mathrm{L}$, equal to $6.00 \mathrm{~m}$, an inclination, $\theta$, equal to $30^{\circ}$ and a width, b, equal to $0.10 \mathrm{~m}$. It is assumed that the flow in the channel is two-dimensional, the regime is steady state turbulent, viscous dissipations are negligible and thermophysical properties are constant with temperature, except for density (Boussinesq approximation), which gives rise to buoyancy forces. Air is the working fluid and its thermophysical properties are calculated at the operative temperature. The governing equations of the simulation are: mass conservation, momentum equation and energy conservation [19]. They are coupled, non-linear and partial differential equations and their numerical solutions are obtained using the commercial code Ansys-Fluent 12.2 [20] by the finite volume method.

As Figure 2 shows, the computational domain has finite dimensions (the roof is placed in an infinite medium) and it is composed by the ventilated channel and two storages located at the inlet and the outlet of the channel. The two storages are useful to know what happens near the region of the thermal disturbance caused by the heat applied on the upper layer of the cavity to simulate the free-stream condition of the flow. Inlet storage dimensions are $\mathrm{Lx}=\mathrm{Ly}=3 \mathrm{~m}$, equal to the average height of a floor. Outlet storage is characterized by the exit section of the channel and the height of the ridge, $h$, is equal to $0.10 \mathrm{~m}$. The geometric model and the mesh of the computational domain are realized thanks to the software Gambit [21]. In particular, to create the mesh, several grids were realized and compared depending on Richardson's extrapolation equation [20], so the chosen grid counts 228427 calculation cells. The choice of the mesh used for simulations, depends on the right compromise between the accuracy of the simulation and calculation time.

In this work, two regimes are studied: summer condition and winter condition. They are numerically simulated thanks to the following boundary condition.

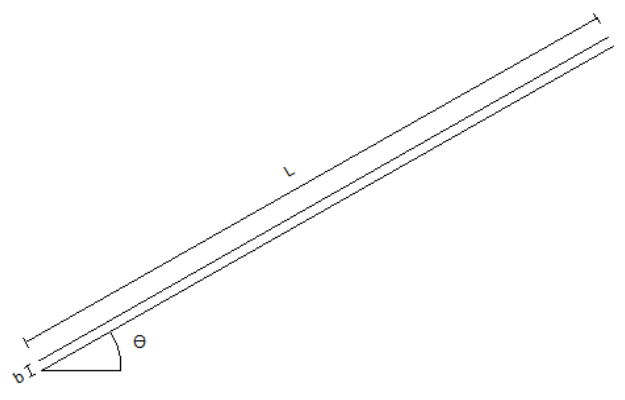

Figure 1. Ventilated channel

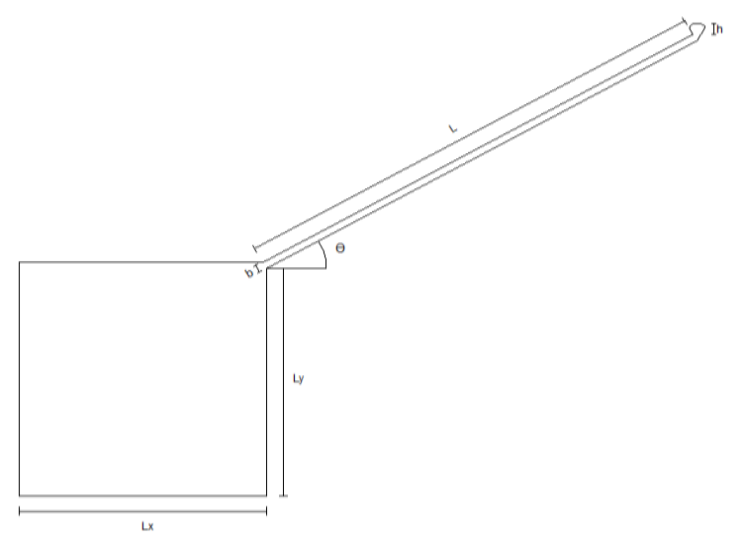

Figure 2. Computational domain

In summer, the operative temperature is equal to $300 \mathrm{~K}$. The bottom wall of the ventilated channel is simulated as isothermal, with $\mathrm{T}=298 \mathrm{~K}$ (optimal ambient condition in summer). In winter, the operative temperature is equal to $275 \mathrm{~K}$. The bottom wall of the ventilated channel is simulated as isothermal, with $\mathrm{T}=293 \mathrm{~K}$ (optimal ambient condition in winter). On the top wall of the cavity, a uniform heat flux is applied and its values depends on the day hours: in a typical summer day, significative heat flux values are reported from 9:00 to 18:00; in a typical winter day, significative heat flux values are reported from 9:00 to 16:00. Values are obtained thanks to the database PVGIS-CMSAF [22], as shown in Table 1.

Furthermore, on the bottom wall of the ventilated channel, the heat transfer coefficient $h$ is equal to $5 \mathrm{~W} / \mathrm{m}^{2} \mathrm{~K}$ to simulate the properties of structure layers under the cavity. On the top wall of the cavity, $h=10 \mathrm{~W} / \mathrm{m}^{2} \mathrm{~K}$ to simulate the properties of structure layers above the cavity; the external emissivity $\varepsilon$ is equal to 0.85 to simulate radiation effects. 
Table 1. Heat flux values in summer and winter conditions

\begin{tabular}{lll}
\hline time & $\mathrm{qs}_{\mathrm{s}}\left[\mathrm{W} / \mathrm{m}^{2}\right]$ & $\mathrm{q}_{\mathrm{w}}\left[\mathrm{W} / \mathrm{m}^{2}\right]$ \\
\hline $09: 00$ & 667 & 310 \\
$10: 00$ & 782 & 410 \\
$11: 00$ & 849 & 467 \\
$12: 00$ & 862 & 478 \\
$13: 00$ & 822 & 444 \\
$14: 00$ & 730 & 365 \\
$15: 00$ & 593 & 245 \\
$16: 00$ & 422 & 81 \\
$17: 00$ & 236 & \\
$18: 00$ & 85 & \\
\hline
\end{tabular}

\section{RESULTS AND DISCUSSION}

The objective of this work is to study the thermal and fluid dynamic behaviors of a ventilated roof in summer and winter regimes. In summer conditions, ten cases are analyzed, varying heat flux value from $667 \mathrm{~W} / \mathrm{m}^{2} \mathrm{~K}$ at 9:00 to 85 $\mathrm{W} / \mathrm{m}^{2} \mathrm{~K}$ at 18:00. In winter conditions, eight cases are analyzed, varying heat flux value from $310 \mathrm{~W} / \mathrm{m}^{2} \mathrm{~K}$ at 9:00 to $81 \mathrm{~W} / \mathrm{m}^{2} \mathrm{~K}$ at 16:00. In the following, two cases are reported for brevity to analyze the seasonal behavior of the ventilated roof: in summer condition, $\mathrm{q}_{\mathrm{s}}=862 \mathrm{~W} / \mathrm{m}^{2} \mathrm{~K}$ at $12: 00$; in winter condition, $\mathrm{q}_{\mathrm{w}}=478 \mathrm{~W} / \mathrm{m}^{2} \mathrm{~K}$ at $12: 00$.

Figures 3(a) and 3(b) report air temperature and velocity fields in summer conditions, showing how heat transfer and air flow are influenced by the heat flux applied on the top wall of the cavity. Temperature values rise in the ventilated channel with the distance from the inlet section, reaching the maximum on the top wall of the cavity, with $\mathrm{T}=345 \mathrm{~K}$. Velocity values are higher near the outlet section of the channel because of the air heating. As shown in Figure 3(c), velocity vectors highlight a vortex increasing values in proximity of the ridge in the outlet reservoir and the maximum velocity value is equal to $0.891 \mathrm{~m} / \mathrm{s}$.

In winter conditions, air temperature and velocity fields, in Figures 4(a) and 4(b), show the same trend: the heat flux applied on the top wall of the cavity influences heat transfer and air flow. Temperature values rise with the distance from the inlet section; the maximum is reached on the top wall of the cavity, near the outlet section, with $\mathrm{T}=303 \mathrm{~K}$. Velocity grows in the channel with the distance from the inlet section because of the air heating and, in proximity of the ridge, velocity vectors highlight a vortex, as shown in Figure 4(c), where values are maximum, equal to $0.880 \mathrm{~m} / \mathrm{s}$.

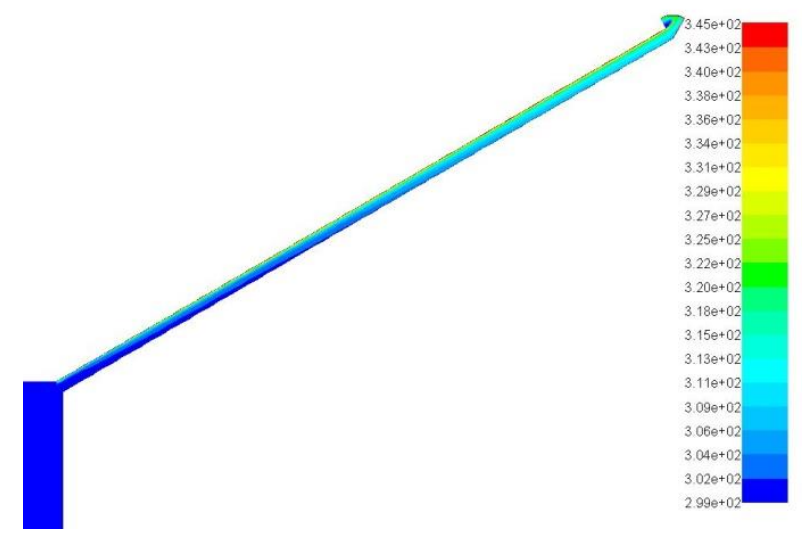

(a) Air temperature field

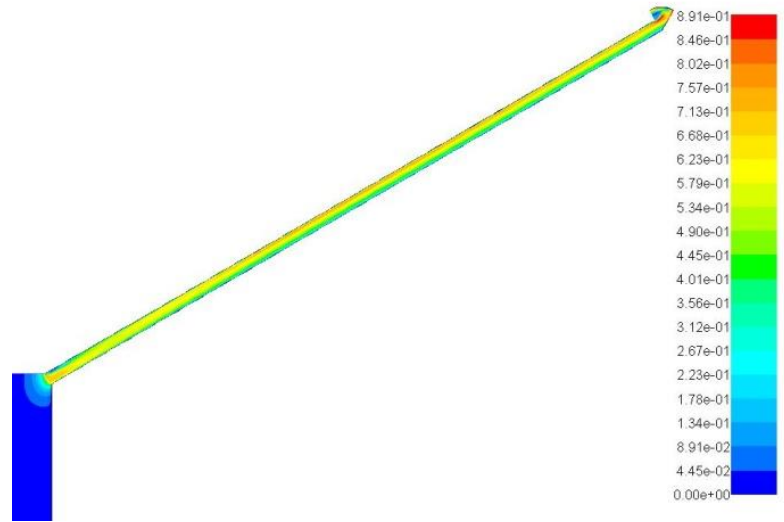

(b) Air velocity field
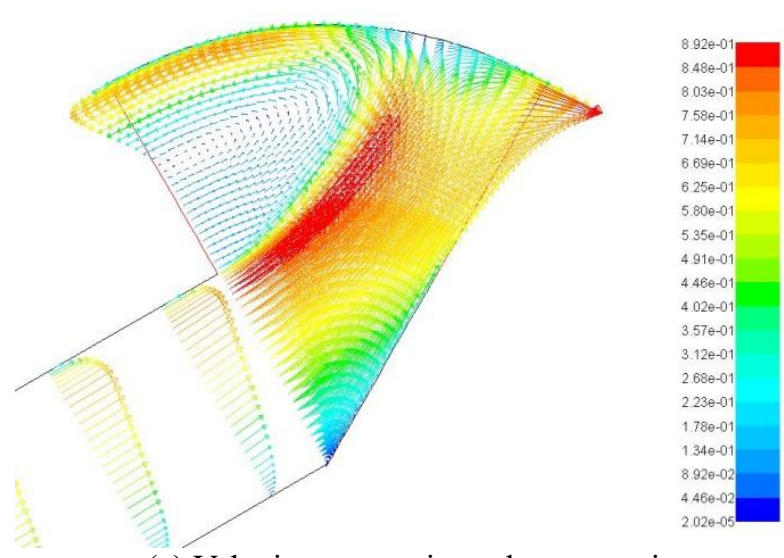

(c) Velocity vectors in outlet reservoir

Figure 3. Summer configuration

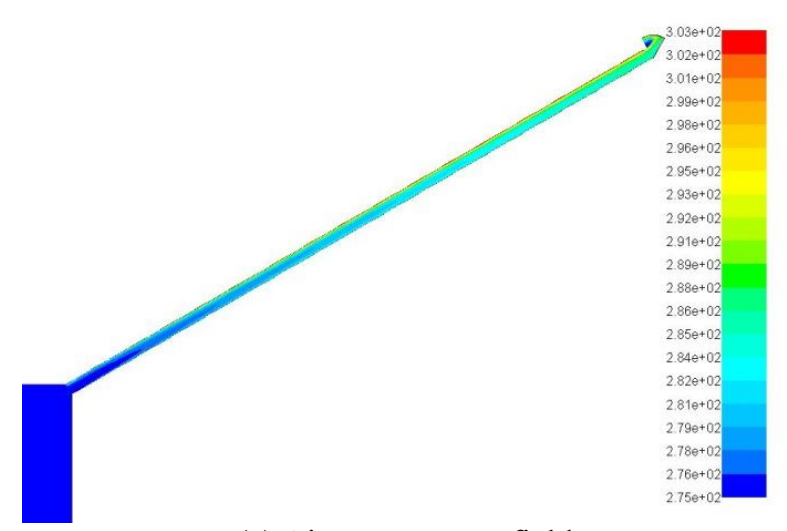

(a) Air temperature field

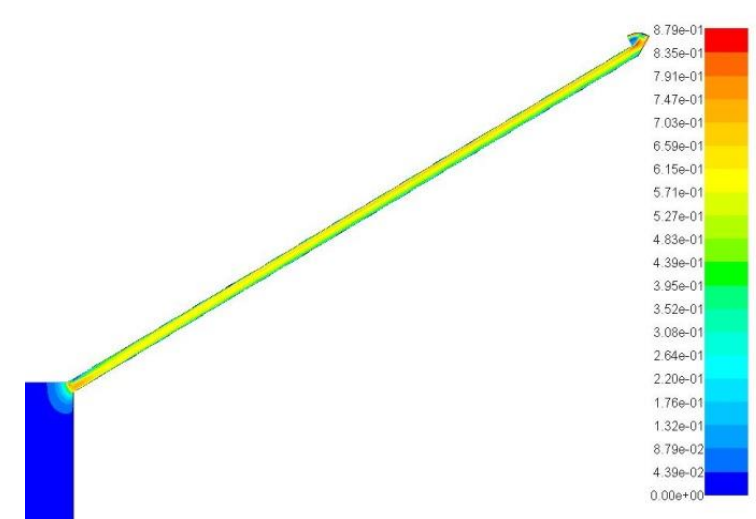

(b) Air velocity field 


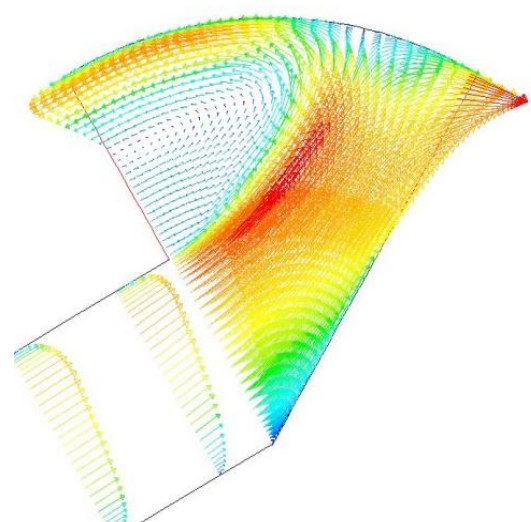

(c) Velocity vectors in outlet reservoir

Figure 4. Winter configuration

Considering five channel section, placed at $1 \mathrm{~m}, 2 \mathrm{~m}, 3 \mathrm{~m}$, $4 \mathrm{~m}$ and $5 \mathrm{~m}$ from the entrance, temperature profiles are shown in Figures 5(a) and 5(b). In summer conditions, temperature values grow in the cavity and they are higher in proximity of the top wall, because part of the heat conveys near the cover and the temperature rise toward the top of the roof. In winter conditions, due to lower ambient temperature and heat flux applied on the top wall, temperature values decrease along X-direction at first, then they grow and reach the maximum on the top wall.

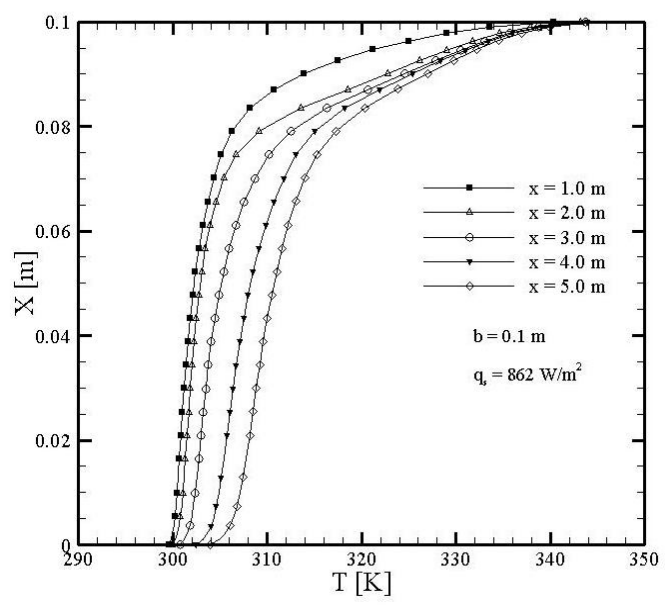

(a) Summer configuration

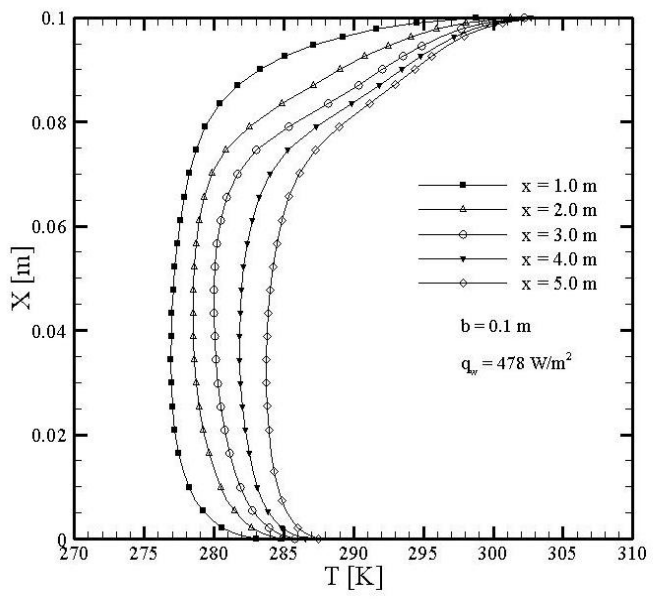

(b) Winter configuration

Figure 5. Temperature profiles in cross sections
In the following, a comparison between summer and winter configurations is reported: results are given in terms of air velocity and temperature profiles along the axis of the channel. Figure 6 shows temperature trend along the axis of the channel in summer and winter conditions. In summer, the profile has a more pronounced fluctuation, but the growth is faster. Figure 7 shows velocity trend along the axis of the channel in summer and winter conditions. In the inlet section, values decrease, then they rise reaching a lower value in the outlet section.

\section{CONCLUSIONS}

A numerical investigation is realized to know the thermal behavior of a prototypal ventilated roof for residential use under variable solar radiation, to simulate summer and winter conditions. The system is composed by a single side of the roof, due to its geometrical and thermal symmetry. The system consists of a ventilated cavity: on the bottom wall, a constant value of temperature is applied to simulate optimal ambient condition in summer and winter periods; on the top wall, a heat flux is applied to simulate solar radiation operating at different hours on typical summer and winter days. In particular, analyzing the thermal behaviors at 12:00, the study has revealed that:

- Temperature increases in the channel with the distance to the inlet section due to the effect on heat transfer and flow air in the channel. The maximum value is reached on the top wall of the cavity, where the effect of the solar radiation is more evident.

- Velocity increases in the channel because of the air heating, so in summer period values are higher. Maximum values are reached in the outlet reservoir, where a vortex increases velocity values in proximity of the ridge.

- Temperature trend is the same along five different cross sections, but higher values are reached at $\mathrm{x}=5.0 \mathrm{~m}$. In summer, values increase in the channel; in winter, due to the bottom wall condition, temperature decreases at first, then maximum value is reached on the top wall of the cavity.

- $\quad$ Along the channel, temperature trend is growing in each condition, but values are higher in summer period, when the effect of solar radiation is more evident thanks to the convective effect within the channel. In winter, the effect of the ventilated layer is very important to reach optimal thermal and hygrometric conditions.

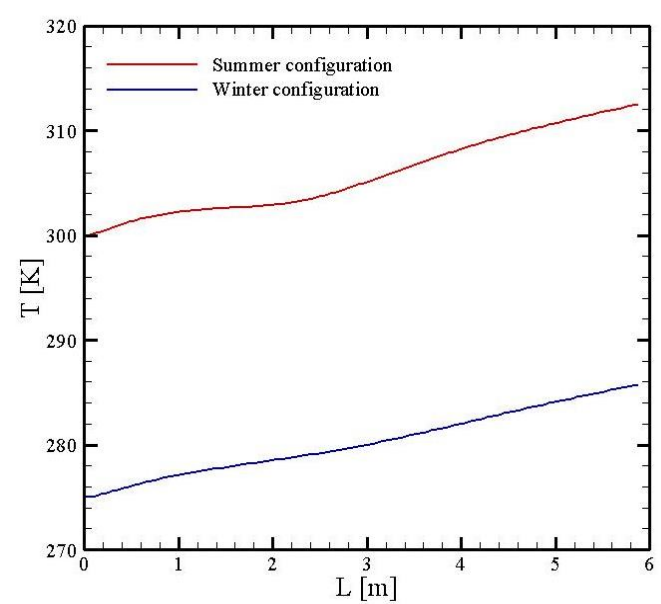

Figure 6. Air temperature profile in the ventilated channel 


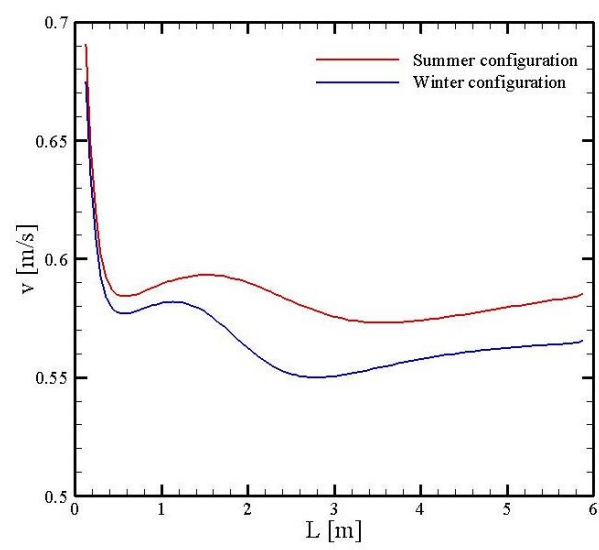

Figure 7. Air velocity profile in the ventilated channel

\section{REFERENCES}

[1] M. Ciampi, F. Leccese and G. Tuoni, "Energy analysis of ventilated and microventilated roofs," Sol. Energy, vol. 79, pp. 183-192, Aug., 2005. DOI: 10.1016/j.solener.2004.08.014.

[2] O. Manca, A. Mangiacapra, S. Marino and S. Nardini, "Numerical investigation on thermal behaviors of an inclined ventilated roof," presented at $12^{\text {th }}$ Biennal Conference on Engineering Systems Design and Analysis ESDA2014, Copenhagen, Denmark, Jun. 2527, 2014.

[3] Y. Tong, J. Zhai, C. Wang, B. Zhou and X. Niu, "Possibility of using roof openings for natural ventilation in a shallow urban road tunnel," Tunn. Undergr. Sp. Tech., vol. 54, pp. 92-101, Apr., 2016. DOI: $10.1016 /$ j.tust.2016.02.004.

[4] C. Lai, J. Y. Huang and J. S. Chiuo, "Optimal spacing for double-skin roofs," Build. Environ., vol. 43, pp. 1749-1754. Oct., $2008 . \quad$ DOI: 10.1016/j.buildenv.2007.11.008.

[5] N. H. Wong and S. Li, "A study of the effectiveness of passive climate control in naturally ventilated residential buildings in Singapore," Build. Environ., vol. 42, pp. 1395-1405, Mar., 2007. DOI: 10.1016/j.buildenv.2005.11.032.

[6] S. Tong and H. Li, "An efficient model development and experimental study for the heat transfer in naturally ventilated inclined roofs," Build. Environ., vol. 81, pp. 296-308, Nov., 2014. DOI: 10.1016/j.buildenv.2014.07.009.

[7] M.B Ozdeniz and P. Hancer, "Suitable roof constructions for warm climates - Gazimagusa case," Energ. Buildings, vol. 37, pp. 643-649, Jun., 2015. DOI: $10.1016 /$ j.enbuild.2004.09.008.

[8] K. T. Zingre, M. P. Wan, S. K. Wong and W.B.T. Toh, "Modelling of cool roof performance for doubleskin roofs in tropical climate," Energy, vol. 82, pp. 813-826, Mar., 2015. DOI: 10.1016/j.energy.2015.01.092.

[9] P. H. Biwole, M. Woloszyn and C. Pompeo, "Heat transfer in a double-skin roof ventilated by natural convection in summer time," Energ. Buildings, vol. 40, pp. 1487-1497, 208. DOI: 10.1016/j.enbuild.2008.02.004.
[10] A. Dimoudi, A. Androutsopoulos and S. Lykoudis, "Summer performance of ventilated roof component," Energ. Buildings, vol. 38, pp. 610-617, Jun, 2006. DOI: $10.1016 /$ j.enbuild.2005.09.006.

[11] A. Gagliano, F. Patania, F. Nocera, A. Ferlito and A. Galesi, "Thermal performance of ventilated roofs during summer period," Energ. Buildings, vol. 49, pp. 611-618, Jun., 2012. DOI: 10.1016/j.enbuild.2012.03.007.

[12] G. Villi, W. Pasut and M. De Carli, "CFD modelling and thermal performance analysis of a wooden ventilated roof structure," Build. Simul., vol. 2, pp. 215-228, Sep., 2009. DOI: 10.1007/s12273-009-94147.

[13] A. Dimoudi, S. Lykoudis and A. Androutsopoulos, "Thermal performance of an innovative roof component," Renew. Energ., vol. 31, pp. 2257-2271, Nov., 2006. DOI: 10.1016/j.renene.2005.10.012.

[14] J. Kosny, K. Biswas, W. Miller and S. Kriner, "Field thermal performance of naturally ventilated solar roof with PCM heat sink," Sol. Energy, vol. 86, pp. 25042514, Sep., $2012 . \quad$ DOI: 10.1016/j.solener.2012.05.020.

[15] Y. Wang, W. Tian, J. Ren, L. Zhu and Q. Wang, "Influence of building's integrated-photovoltaics on heating and cooling loads," Appl. Energ., vol. 83, pp. 989-1003, Sep., 2006. DOI: 10.1016/j.apenergy.2005.10.002.

[16] S. N. Kharrufa and Y. Adil, "Upgradng the building envelope to reduce cooling loads," Energ. Buildings, vol. 55, pp. 389-396, Dec., 2012. DOI: 10.1016/j.enbuild.2012.09.006.

[17] L. Cirillo, D. Di Ronza, V. Fardella, O. Manca and S. Nardini, "Numerical and experimental investigation on a solar chimney integrated in a building façade", Int. J. Heat Tech., vol. 33 (4), pp. 246-254, 2015. DOI: http://dx.doi.org/10.18280/ijht.330433

[18] B. Buonomo, O. Manca, S. Nardini and P. Romano, "Thermal and fluid dynamic analysis of solar chimney building systems", Int. J. Heat Tech., vol. 31, no. 2, pp. 119-126, 2013.

[19] Handbook of Heat Transfer, $3^{\text {rd }}$ ed., McGraw-Hill.

[20] ANSYS-Fluent Inc. Ansys-Fluent 12.2 manuals. Ansys ed. 2012.

[21] Fluent-Inc. Gambit 2.4 Modeling Guide ed. 2007.

[22] http://www.consiglioenergia.it/joomla/utilita/calcola-lirraggiamento.

\section{NOMENCLATURE}

b Channel width, $m$

$\mathrm{h} \quad$ Hipped roof height, $\mathrm{m}$

L Channel length, $m$

$\mathrm{L}_{\mathrm{x}}, \mathrm{L}_{\mathrm{y}}$ Inlet reservoir dimensions, $\mathrm{m}$

$\mathrm{h} \quad$ Height of the ridge, $\mathrm{m}$

$\mathrm{q}_{\mathrm{s}} \quad$ Heat flux in summer, $\mathrm{W} / \mathrm{m}^{2}$

$\mathrm{q}_{\mathrm{w}} \quad$ Heat flux in winter, $\mathrm{W} / \mathrm{m}^{2}$

$\mathrm{T}$ Operative temperature, $\mathrm{K}$

$\mathrm{T}_{\mathrm{s}} \quad$ Temperature in summer regime, $\mathrm{K}$

$\mathrm{T}_{\mathrm{w}} \quad$ Temperature in winter regime, $\mathrm{K}$

$\theta \quad$ Roof inclination, ${ }^{\circ}$

$\mathrm{k} \quad$ Kinetic energy of turbulence

$\varepsilon \quad$ Turbulent kinetic energy dissipation 